HPB Surgery 1989, Vol. 1, pp. 171-172

Reprints available directly from the publisher

Photocopying permitted by license only
(C) 1989 Harwood Academic Publishers GmbH Printed in Great Britain

\title{
HPB NEWS
}

\section{HPB CHAPTER IN SOUTH AFRICA}

The south african members have organized a national chapter. It has elected officers from all 7 university medical schools. The present committee consists of:

J. Terblanche, Cape Town

J.A. Myburgh, Johannesburg

J. Krige, Cape Town

P.C. Bornman, Cape Town

L.C. van Rensburg, Stellenbosch

C.J. Nel, Bloemfontein

J.A. van Wyk, Medunsa

E.M. Barker, Natal

H.H. Lawson, Johannesburg

V.O.L. Karusseit, Pretoria
Chairman and national delegate

Vice-chairman

Secretary/treasurer

Committee member

Committee member

Committee member

Committee member

Committee member

Committee member

Committee member

\section{IHBPA PREVIOUSLY IBA}

The above held its annual meeting in Nice last September. The meeting had 452 participants. The membership is 225 and 53 new members were admitted. The 1988/89 council is: D.C. Carter (UK), President; A.R. Moossa (USA), Presidentelect; R. Praderi (Uruguay), Vice president; D.L. Carr-Locke (UK), Secretarytreasurer; J. Garden (UK), Associate secretary; E. Seifert (FRG), Associate treasurer; J. Toouli, T. Osuga, H. Bismuth, H.C. Peiper, I. Ihse, L.H. Blumgart, J. Puig La Calle, F. Nakayama, H. Debas, D. d'Amico, E. Van Sonnenberg, J. Mouiel, council members.

On alternate years $(1989,1991,1993$ etc.) the IHBPA will meet in association with the World Congress of Surgery under the aegis of the International Society of Surgery (ISS) and Collegium Internationale Chirurgiae Digestivae (CICD). In the corresponding alternate years $(1990,1992$ etc.), the association will meet in close proximity to a World or International Congress of Gastroenterology/ Endoscopy. Thus the coming meetings will be 1989: Toronto; 1990: Hong Kong; 1991: Stockholm; 1992: South America. R. Keith is the local organizer in Toronto.

The association wants to achieve greater standards in world clinical and scientific medicine as an independent high-quality scientific organization offering a unique multidisciplinary forum for critical discussion of all forms of research in hepatic, biliary and pancreatic fields.

The Frank Glenn Fellowship, (5000 Swiss Francs), was given to Dr. Giovanni Aloj for his work: "Relationships amongst bile stasis, sepsis and choledocholithiasis: clinical and experimental studies."

The meeting in Nice marked the 10thy anniversary of the association. 
The address to the secretary-treasurer is:

Dr. D.L. Carr-Locke

Gastroenterology Unit

Leicester Royal Infirmary

Leicester, UK.

Tel. (0533) 541414 ext. 240

\section{WORLD ASSOCIATION OF HPB SURGERY}

On December 31st, 1988 the association had 1772 members. The largest membership is in Italy (262 members), USA ( 99 members), Great Britain ( 87 members), and West Germany (73 members).

The 1988/1990 Council consists of Martin Adson (USA), President; Bernard Langer (Canada), Vice President; Niels van der Heyde (Netherlands), President elect; Stig Bengmark (Sweden), General Secretary; Robin Williamson (Great Britain), Treasurer; Miles Little (Australia); Christoph Broelsch (USA); Arthur Li (Hong Kong); Henry Pitt (USA); John Terblanche (South Africa); Hans Beger (FRG); Enrique Moreno Gonzales (Spain); Giuseppe Gozzetti (Italy) and members at large.

The 1988/1990 Scientific Committee is: Christoph Broelsch (USA), Chairman; Irving Benjamin (Great Britain); Peter Fabri (USA); Dominique Franco (France); John Ham (Australia); Ken Hobbs (Great Britain); Bengt Jeppsson (Sweden); Bernd Kremer (FRG); Dr. Lam (Japan); Huug Obertop (Netherlands); Malcolm Puntis (Great Britain); Johannes Scheele (FRG); Paul Sugarbaker (USA); Onno Terpstra (Netherlands); T. Tobe (Japan).

The third HPB World Congress will take place in Kensington Town Hall in London, 4th-8th June 1990. A large national committee consisting of Robin Williamson, Ken Hobbs, Irving Benjamin, Malcolm Puntis and several others are working hard to prepare a good meeting. Detailed news about the meeting will follow in the next issue.

The address to the secretary is:

Professor Stig Bengmark

Box 5003

S-220 05 Lund 5

Sweden

Tel. int. 46-46-171160, telefax int. 46-46-172335. 


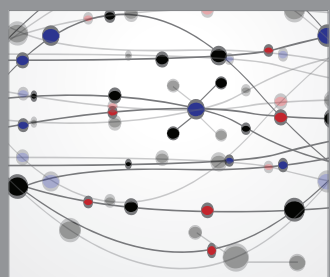

The Scientific World Journal
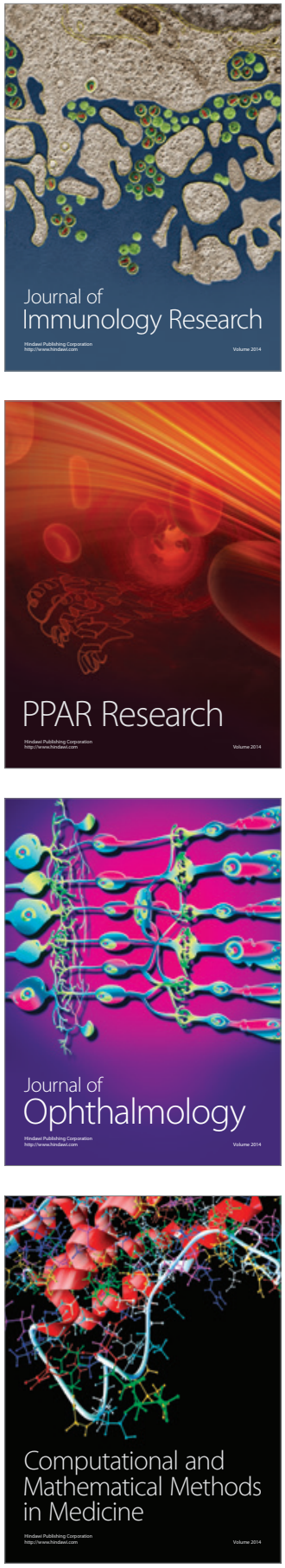

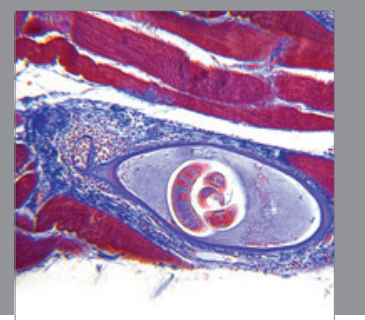

Gastroenterology

Research and Practice
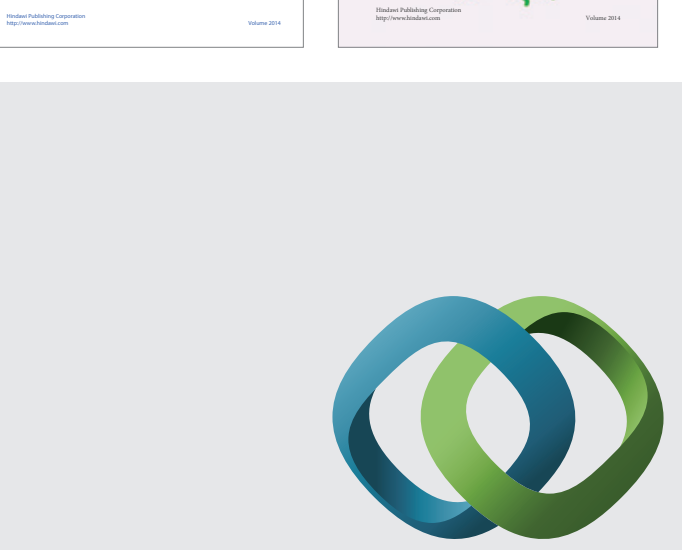

\section{Hindawi}

Submit your manuscripts at

http://www.hindawi.com
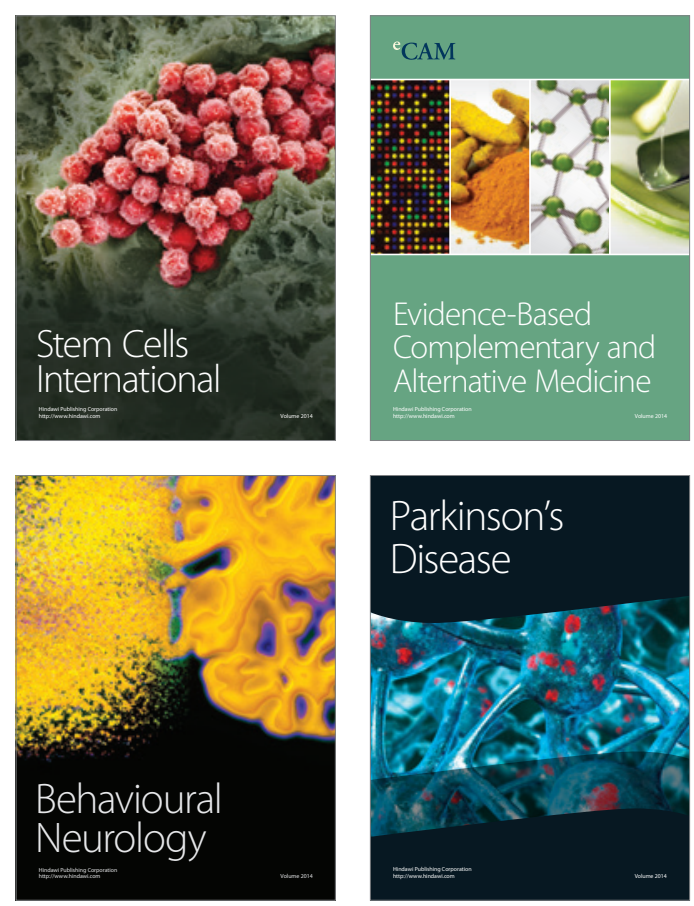

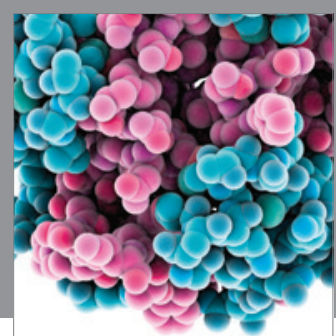

Journal of
Diabetes Research

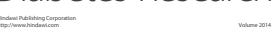

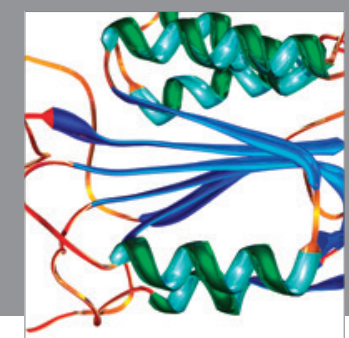

Disease Markers
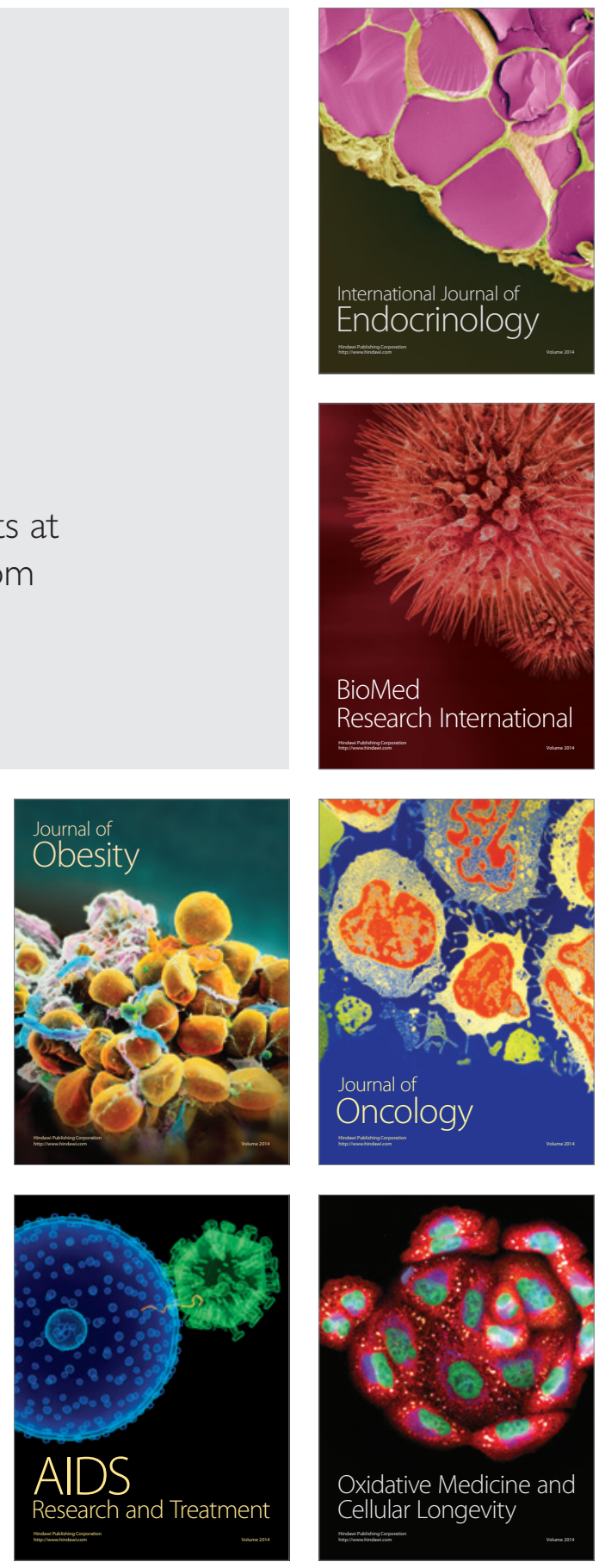